Western University Scholarship@Western

Centre for the Study of International Economic Centre for the Study of International Economic

Relations Working Papers

Relations

1985

\title{
The Real Interest Rate and Aggregate Supply
}

Zvi Hercowitz

Follow this and additional works at: https://ir.lib.uwo.ca/economicscsier_wp

Part of the Economics Commons

Citation of this paper:

Hercowitz, Zvi. "The Real Interest Rate and Aggregate Supply." Centre for the Study of International Economic Relations Working Papers, 8520C. London, ON: Department of Economics, University of Western Ontario (1985). 
CENTRE FOR THE STUDY OF INTERNATIONAL ECONOMIC RELATIONS

WORKING PAPER NO. 8520C

THE REAL INTEREST RATE AND

AGGREGATE SUPPLY

Zvi Hercowitz

This paper contains preliminary findings from research work still in progress and should not be quoted without prior approval of the author.

DEPARTMENT OF ECONOMICS THE UNIVERSITY OF WESTERN ONTARIO LONDON, CANADA

N6A $5 \mathrm{C} 2$
Department of Economics Librery

SEP 51985

University of Wottom Ontario 
THE RRAL INTEREST RATB AND

\title{
AGGREGATE SUPPLY
}

\author{
Zvi Hercowitz
}

\author{
Tel-Aviv University \\ University of Western Ontario \\ Rochester Center for Economic Research
}

August, 1985

I thank Robert Barro, Dominique Demougin, Jeremy Greenwood, Peter Howitt, Robert King, Michael Parkin and Mike Veall for helpful comments and discussions.

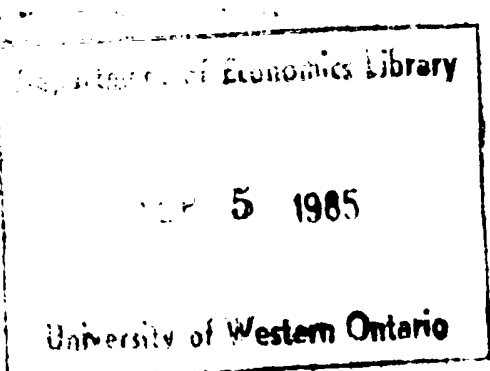




\section{Introduction}

The role of the intertemporal substitution of labor supply has been stressed in the recent business cycle literature, notably by Lucas and Rapping (1969), Hall (1980), Barro (1981a, 1981b) and Kydland and Prescott (1982). By this mechanism, higher real interest rates stimulate work effort and hence aggregate supply. This paper investigates the importance of an additional intertemporal mechanism pertinent to labor demand, involving investment and capital utilization, which works in the opposite direction.

A basic premise is that production involves time. It implies that labor and other costs have to be financed during the production process and hence, production becomes an investment type of decision. This notion is very old in the economic literature. It is embodied in the classical wages-fund doctrine associated with John Stuart Mill (1909), and it is discussed in detail by Böhm-Bawerk (1923). Böhm-Bawerk (p. 88) argues that the time factor may not seem important when considering an individual producer at a particular stage of the social production process, but it is important for the economy as a whole, where all stages of production are involved. This argument also seems relevant for modern macroeconomic models, using the paradigm of the representative firm or producer. The production process of the representative firm can be seen as a lengthy one, extending from the extraction and early processing of raw materials through to retail trade.

Recently, Grossman and Weiss (1982) have incorporated a production lag in a macro model. Since in this setup current labor input produces output in the future, the marginal return to labor effort is the present value of its 
marginal productivity. Hence, labor input and production tend to be negatively affected by the anticipated real interest rate. Long and Plosser (1983) also specify a production lag in their real business cycle model. However, in the example that they fully work out, labor input is time-invariant due to the logarithmic utility function used. Kydland and Prescott (1982) have stressed the importance of another type of delay, in the form of a multiple period time-to-build for new productive capital, in the propagation of business cycles.

In the model described in section II, the representative firm faces considerations which partly reflect those stressed by Grossman and Weiss. Since the return on current productive activity is the present value of the future finished products, this return declines with the anticipated real interest rate, and so does current labor demand. In the present model, this mechanism also has an important link with the investment and the capital utilization decisions. The real interest rate has a negative effect on current investment demand, which in turn lowers the user cost of capital utilization. If capital services and labor input are complements in production, the negative effects of the interest rate on labor demand and capital utilization strengthen each other.

Using the usual setup without a production lag, King (1980) and Merrick (1984) have derived an opposite prediction regarding the effect of the real interest rate on labor demand and capital utilization. In their setups a more intensive capital utilization is essentially the way to achieve a lower net investment. Since the latter is desired under high real interest rates, and given the complementarity between capital services and labor input, the interest rate has a positive effect on labor demand. The difference in the 
results is due to the production lag that is introduced here, which breaks the correspondence between the choice of more intensive utilization on the one hand and less investment on the other. This point is elaborated in the next section.

The labor supply side of the model is derived from a standard dynamic optimization problem of a representative individual who chooses consumption and leisure. Since the real interest rate has a positive effect on labor supply, it affects the equilibrium level of employment in two opposite directions. Hence, an interesting problem regarding the net employment effect is present. Under standard assumptions, the present framework predicts that the negative effect on labor demand prevails.

Given this negative response of equilibrium labor input, and the reinforcing movement of capital utilization, the real interest rate is predicted to have a negative effect on output, resulting in a positive co-movement in these three variables. Because of the variable capital utilization, average labor productivity is also likely to be procyclical. Although the paper focuses on aggregate supply, the model also predicts a standard negative effect of the interest rate on investment and consumption. Basically, the results of the model can be summarized as predicting that lower interest rates have an expansionary effect, not only on aggregate demand, but also on aggregate supply.

It should be stressed that a significant production period is crucial for these results to hold. With instantaneous production the employment and output effects of the interest rate are reversed and the effect on capital utilization disappears. In this case the positive influence on employment and output follows from the remaining intertemporal substitution in labor supply. 
This represents the null hypothesis against which the present model is tested. To analyze and test these effects on aggregate supply variables it is convenient to avoid the general equilibrium problem by modelling a competitive small open economy under perfect capital markets. In this case the real interest rate can be modelled, and empirically treated, as exogenous. The model is tested using Canadian data, taking the real interest rate in the United states as that prevailing in the international capital market. The Canadian case is especially attractive in this context because it is probably as close as a real economy can get to the type of open economy modelled.

By adopting this partial equilibrium strategy, this project has a more limited scope than a closed-economy general equilibrium model. However, I believe that this analysis can contribute to the understanding of business cycles in general. The present framework is able to generate a positive co-movement of macroeconomic variables, in response to an intertemporal relative price, that seems to correspond to those usually observed in business cycles. Barro and King (1984) address the problems in generating these co-movements from a framework--like the present one--that incorporates time-separable preferences.

Section II of this paper describes the general analytical framework. Section III introduces specific functional forms to derive an econometrically implementable model. The construction of real interest rate measures is discussed in Section IV. Section $V$ reports the construction of an adjusted capital stock series, to incorporate the notion of 'user cost' employed in the model. The results from empirical tests are reported in Section VI, and they provide support for the implications of the model. The last section summarizes the results. 


\section{Practical Importance of the Production Period}

Given its crucial theoretical role, it is important at this point to comment on the order of magnitude of the production lag in practice.

The empirical counterpart of the production period of the representative firm is the time elapsed from the early stages of production to the distribution to consumers. As a rough approximation, this period is treated as constant in the model described below. The consideration of a variable delivery lag (see Carlton (1979)) is a possible extension of the present framework, although at present I do not have specific plans in this direction.

An idea of the length of this period can be obtained by looking at the ratio of inventories in all stages of production (raw materials, goods in process and finished goods) to the total value added per period. In this framework all these inventories are thought of as goods in process and they represent the working capital required for production (including distribution). Using Canadian data for manufacturing, wholesale trade and retail trade--sectors for which data on inventories were available--the ratio of total inventories to annual value added ranges from 0.58 to 0.67 during the period 1971-1983. For a representative $f$ irm, such a ratio can be roughly translated into a production period of 14 to 16 months. ${ }^{1}$ Although this is a very crude estimate, it suggests that for manufactured goods the time involved in production may be an important consideration.

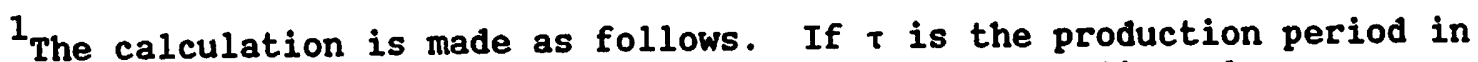
months during which the monthly value added $f$ accumulates linearly, average inventories--over time for one firm or across firms at one point in time--are given by $I=(\%) f \cdot \tau$. Annual value added is $Y=12 f$. Substituting and rearranging yields $\tau=24 I / Y$. 
II. The Model

Consider an economy populated by identical households and identical firms interacting in a competitive environment. There is only one good that can be used either for consumption or investment. Given the small open economy assumption, real interest rates are exogenously given from the international capital market. Hence, considering labor services as non-tradable across countries, the wage rate is the only endogenous price.

The existence of a production period is modelled by assuming that it takes one period (say one year) to produce the homogeneous good. This technology is described by

$$
Q_{t+1}=Y_{t}=F\left(L_{t}, K_{t}, H_{t} / \ldots\right) \quad F_{\ell}, F_{k}, F>0, F_{\ell \ell}, F_{k k}, F_{h h}<0,
$$

and positive cross derivatives, where $Y_{t}$ is the production flow during period $t$, reflected in the flow of finished products $Q_{t+1}$ in $t+1$. The arguments of the production function are: $L_{t}$, labor input in time units, $K_{t}$, the stock of physical capital at the beginning of period $t$, and $H_{t}$, the rate of capital utilization during period $t\left(H_{t} \leq 1\right) . \quad K_{t}$ and $H_{t}$ may enter the production function multiplicatively as a special form. The dots represent exogenous productivity shifts which do not affect the theoretical discussion in this section.

However, to facilitate the subsequent empirical implementation of the model, the form of $F$ in equation (1) is seen as resulting from the underlying technology

$$
Y_{t}=\bar{F}\left(L_{t} N_{t}, K_{t}, H_{t} / G_{t}, t, \varepsilon_{2 t}\right)
$$

where $\mathbb{N}_{t}$ is human capital, determining the quality of labor input, $G_{t}$ is government purchases of goods and services, affecting productivity, $t$ 
reflects technological progress and $\varepsilon_{2 t}$ is a random productivity shock. $w_{t}$ follows the exogenous process $N_{t}=N\left(t, \varepsilon_{1 t}\right)$, where $t$ captures human capital improvement and $\varepsilon_{1 t}$ is a random shock to this process. Substituting $\mathbb{W}_{t}$ into (2) yields the specific counterpart of (1):

$$
Q_{t+1}=Y_{t}=F\left(L_{t}, K_{t}, H_{t} / G_{t}, t, \varepsilon_{t}\right)
$$

where $\varepsilon_{t}=\left(\varepsilon_{1 t}, \varepsilon_{2 t}\right)$. The empirical motivation for including government purchases follows Ahmed's (1985) results, which indicate a positive and significant productivity effect of government purchases using U.K. data. The results in Barro (1981) also suggest such an effect in the U.S. Hence, econometric efficiency may be improved by including this variable.

An important feature of the production function is the variable capital utilization rate. The firm's decision about capital utilization involves Keynes's notion of 'user cost'. The depreciation of the capital stock depends on the extent to which it is used. Additionally, the technology requires a one-period time-to-build of new productive capital. Gross investment in period $t, I_{t}$, becomes part of the capital stock only at the beginning of $t+1$. Similarly as in Taubman and Wilkinson (1970) and Merrick (1984), the evolution of the capital stock over time is then formalized as

$$
K_{t+1}=\left(1-\delta H_{t}\right) K_{t}+I_{t}, \quad 0<\delta \leq 1 .
$$

The firm chooses the state-contingent plans for $L_{t+j}^{d}$ (labor demand), $H_{t+j}$ and $I_{t+j}, j=0,1, \ldots$ such as to maximize its net worth

$$
\frac{Q_{t+1}}{1+r_{t}}-w_{t} L_{t}^{d}-I_{t}+E_{t}\left[\sum_{j=1}^{\infty} \sum_{i=0}^{j}\left(\frac{1}{1+r_{t+i}}\right) Q_{t+1+j}-\prod_{i=0}^{j-1}\left(\frac{1}{1+r}\right)\left(w_{t+i}{ }_{t+j}^{L}{ }_{t+j}^{d}-I_{t+j}\right)\right],
$$


subject to the production function, the capital evolution equation and the current stock $k_{t}$. The relevant prices are the real wages $w_{t+j}$ and the one-period real interest rates $r_{t+j}$--pertinent to borrowing/lending between $t+j$ and $t+j+1$. The expectation operator $E_{t}$ is conditioned on full current information. To simplify the analysis, $r_{t}$ is assumed to be known with certainty at time $t$. This makes it possible to take $Q_{t+1} /\left(1+r_{t}\right)$ outside the expectation operator.

The representative household maximizes the time-separable utility function

(4) $\quad E_{t} \sum_{j=0}^{\infty} \beta^{j} U\left(C_{t+j}, L_{t+j}^{s}, \ldots\right), 0<\beta<1, \quad U_{c},-U_{\ell}>0, U_{c c}, U_{\ell \ell}<0$, from the flows of consumption and labor supply. The dots represent exogenous state variables affecting utility that do not affect the present theoretical discussion. For empirical purposes, however, the form of (4) is seen as following from the underlying one-period utility function

$$
\overline{\mathrm{U}}\left(\mathrm{c}_{t}, \mathrm{z}_{t}\right), \quad \overline{\mathrm{U}}_{\mathrm{c}}, \overline{\mathrm{U}}_{\mathrm{z}}>0, \overline{\mathrm{U}}_{\mathrm{cc}}, \overline{\mathrm{U}}_{\mathrm{zz}}<0,
$$

where $z_{t}$ is an index of quality-adjusted leisure. The value of $z_{t}$ is determined by

$$
z_{t}=\left[L-g\left(L_{t}^{s}\right)\right] \mathbb{N}_{t} \quad g^{\prime}>0, g^{\prime \prime}>0
$$

$L$ is the total amount of time available per period and the function $g$ reflects a fatigue effect. Then, $L-g\left(L^{s}\right)$ is the time spent in leisure activities excluding rest. Following Heckman (1976), equation (6) incorporates the notion that human capital determines the quality of leisure. Since $w_{t}=w\left(t, \varepsilon_{1 t}\right)$, the substitution of (6) into (5) yields the specific form of (4): 
(4') $\quad E \sum_{t=0}^{\infty} \beta^{j} U\left(C C_{t+j}, L_{t+j}^{s} / t, \varepsilon{ }_{1 t}\right)$.

The asset accumulation constraint is

$$
A_{t+1}=\left(1+r_{t}\right)\left(A_{t}+w_{t} L_{t}^{S}+D_{t}-T_{t}-C_{t}\right)
$$

where $A_{t}$ is the value of assets at the beginning of period $t, D_{t}$ is the current dividends from the firms and $T_{t}$ is a lump-sum tax.

The issue to be analyzed in this framework is the effect of the current real interest rate on the aggregate supply variables: equilibrium labor input, capital utilization and output. Rather than discussing the effects on the households and the firms' decisions separately and then analyzing the equilibrium outcome, a more convenient procedure is to address the social planner's problem. Assuming no population growth, this problem is to maximize

(4') $\quad E \sum_{j=0}^{\infty} \beta^{j} U\left(C_{t+j}, L_{t+j} / t, \varepsilon{ }_{1 t}\right)$,

subject to

$$
\begin{aligned}
& Q_{t+1}=Y_{t}=F\left(L_{t}, K_{t}, H_{t} / G_{t}, t, \varepsilon_{t}\right), \\
& K_{t+1}=K_{t}\left(1-\delta H_{t}\right)+I_{t}, \\
& A_{t+1}=\left(1+r_{t}\right)\left(A_{t}+Q_{t}-G_{t}-I_{t}-C_{t}\right),
\end{aligned}
$$

the exogenous sequence $G_{t+j}, j=0, \ldots, \infty$ and $k_{t}$, with respect to contingency plans, for $C_{t+j}, L_{t+j}, H_{t+j}$ and $I_{t+j}, j=0, \ldots, \infty$.

Equation ( 7 ) is the capital account of the economy. It is obtained by substituting $D_{t}=Q_{t}-w_{t} L_{t}-I_{t}$ and the government budget constraint $G_{t}=T_{t}$ into the household's asset accumulation equation. The first equality implies the 
assumption that the domestic firms are $100 \%$ owned by domestic households. For a small open economy this will not be true in general, and for the case of Canada--the country for which the model is implemented--it is not. However, this point is not crucial for the effects discussed. The government budget constraint can be generalized to include borrowing and lending without altering the model. This is so because of perfect capital markets and lump-sum taxation.

The current choices of $A_{t+1}, L_{t}, H_{t}$ and $I_{t}$ (all of which imply $C_{t}$ ) involve the following set of optimality conditions:

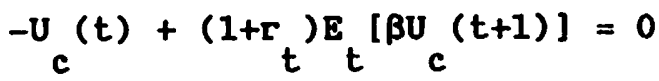

$$
U_{\ell}(t)+F_{\ell}(t) E_{t}\left[\beta U_{c}(t+1)\right]=0
$$
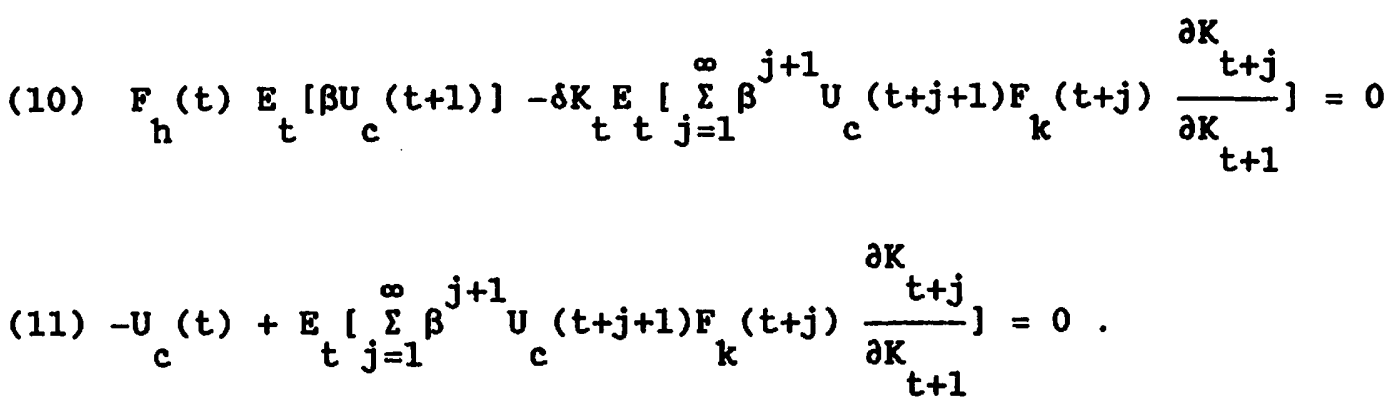

The omitted arguments of the derivatives of $U$ and $F$ are the same as in the functions $U$ and $F$ respectively and they correspond to the time period indicated. In general, this is a very complicated system. However, under fairly standard assumptions it is possible to use (8)-(11) to draw some conclusions about the effect of the real interest rate on the current decision variables. More definite answers are obtained in the next section when specific utility and production functions are used.

Equation ( 8 ) is the standard intertemporal condition for consumption and asset accumulation. The optimality condition for work effort is given by (9), 
where it depends positively, as usual, on marginal productivity. However, the important feature of this condition is that, given the production lag, labor marginal productivity is evaluated at the expected future marginal utility from consumption. This implication is stressed by Grossman and Weiss (1982).

From (8) and (9) this implies that the marginal rate of substitution between consumption and leisure should satisfy

$$
-\frac{U_{\ell}(t)}{U_{C}(t)}=\frac{F_{\ell}(t)}{1+r_{t}},
$$

where the social return to labor effort in terms of current consumption units is the present value of the marginal productivity of labor. A lower interest rate generates a substitution effect, away from leisure and towards consumption, similar to that of higher labor productivity. However, the interest rate has also the more familiar intertemporal substitution effect that works in the opposite direction: lower $r_{t}$ tends to discourage the current supply of labor. Under time-separable preferences, this works as an income effect, i.e., through $U_{c}(t)$ in (9) (see Barro and King (1984)). The presumption here is that this effect is somewhat weaker than the previous one. This presumption implies that the intertemporal reallocation of consumption towards the present, following a decline in $r_{t}$, tends both to lower $U_{c}(t)$ and to increase $E_{t}\left[U_{c}(t+1)\right]$ so as to satisfy (8). In this case, taken as the typical one, the adjustment in $U_{c}(t)$ (the income effect) does not fully offset the shift in $1+r_{t}$ (the substitution effect).

A more important effect of $r_{t}$ on labor effort, which reinforces the previous net negative effect, works through the capital utilization rate and the marginal productivity of labor. In order to analyze this channel, 
consider the capital utilization and investment optimality conditions in (10) and (11). The first term in (10) is the expected marginal benefit in period $t+1$ from increasing the current use of capital. In the second term, $\delta K_{t}$ is the current marginal depreciation of the existing stock, which, from (3), negatively affects $k_{t+1}$. Since lower $k_{t+1}$ implies fewer finished goods in periods $t+2$ and beyond, the expectation expression multiplying $\delta k_{t}$ evaluates those output losses at the corresponding marginal utilities. Hence, the second term is the utility cost of capital utilization.

Equation (11) is a standard optimal investment condition. Assuming an interior solution, it equates the present marginal cost of investment to the expected marginal product of capital from $t+2$ onwards, in utility terms.

Consider now the effects of the real interest rate on investment and capital utilization. The standard negative effect of $r_{t}$ on $I_{t}$ can be obtained from (8) and (11). From (8) a decline in $r_{t}$ tends to reduce the current marginal utility from consumption and to increase the expected future ones. Hence, it tends both to lower the utility cost of investment and to raise its returns. To satisfy (11) the future values of $F_{k}$ are then reduced by increasing current investment. Capital utilization, on the other hand, is not directly affected by $r_{t}$ (it does not include $U_{c}(t)$ ). This is so because it involves a choice of more output in $t+1$ against less output in $t+2$ and beyond. However, the effect of $r_{t}$ on $H_{t}$ is indirect. If lowering $r_{t}$ generates higher investment and thus lower $F_{k} \cdot s$ in the future, it reduces the productivity losses that determine the cost of current capital utilization. This can be seen in the second term of (10). This effect can be algebraically sharpened by substituting (11) into (10), and using (8), to obtain the simple expression 


$$
F_{h}(t)=\delta_{t} K_{t}\left(1+r_{t}\right)
$$

where the tendency of the interest rate to affect capital utilization negatively follows from standard properties of the production function, and the fixity of $k_{t}$ at $t$.

This stands in contrast to the results obtained by King (1980) and Merrick (1984) using an instantaneous production setup. In that case, the effect of the interest rate on capital utilization follows from the similarity of the decisions regarding more investment and less capital utilization. Both are alternative ways to increase the future capital stock (and hence the output of finished products), at the expense of current spending or loss in revenue. The present assumption about the production structure breaks this correspondence.

Assuming now that labor and capital services are complements in production, their choices interact positively in (9) and (10). Hence, the effect of the real interest rate on the social return to labor supply-- $F_{\ell}(t) /\left(1+r_{t}\right)$--involves both the direct effect due to discounting and the indirect increase in labor productivity. The theoretical presumption is that the ensuing substitution effects on labor effort dominate the income effects. This co-movement of capital utilization and labor input leads to the main prediction of the model, which is that the real interest rate has a negative influence on current production.

Although this paper focuses on aggregate supply, it is interesting to note that the present model predicts a positive co-movement of production, labor input, consumption and investment, typical of the business cycle phenomena, in response to a movement of the real interest rate in the opposite direction. Barro and King (1984) stress that this co-movement cannot be 
obtained, as a response to an intertemporal relative price shift, from a model with time-separable preferences and the standard production technology. In this setup, so long as there are no exogenous productivity shifts, labor input and consumption move in opposite directions. It should be stressed, therefore, that the existence of a significant production lag is crucial for the predictions obtained above.

\section{An Empirical Formulation}

The choices of labor effort and capital utilization determine current production, $Y_{t}$, along with the predetermined capital stock and the exogenous variables. However, in the setup described above, the decisions about $L_{t}$ and $H_{t}$ interact with the consumption choice and hence depend in general on the distribution of the entire future path of the exogenous variables. In order to obtain a closed-form solution for the model, suitable for econometric use, the following specific forms are chosen. The basic utility function in equation (5) is specialized to

$$
U\left(c_{t}, z_{t}\right)=\frac{1}{1-\gamma}\left[\phi_{1} c_{t}+\phi_{2} z_{t}\right]^{1-\gamma}, \quad \gamma, \phi_{1}, \phi_{2}>0
$$

the quality-adjusted leisure function--equation (6)--to

$$
\mathrm{Z}_{t}=\left[\mathrm{L}-\mathrm{g}\left(\mathrm{L}_{t}\right)\right] \mathrm{N}_{t}=\left[\mathrm{L}-\frac{1}{1+\theta} \mathrm{L}_{t}^{1+\theta}\right] \mathrm{N}_{t}, \quad \theta>0,
$$

and the human capital process to

$$
\mathbb{N}\left(t, \varepsilon_{1 t}\right)=\exp \left(\lambda_{1} t+\varepsilon_{1 t}\right)
$$

Substituting $w\left(t, \varepsilon_{1 t}\right)$ and $z_{t}$ into (14), yields the empirical counterpart of the utility function in (4'): 
(15)

$$
U\left(c_{t}, L_{t} / t, \varepsilon_{1 t}\right)=\frac{1}{1-\gamma}\left[\phi_{1} C_{t}+\phi_{2}\left(L-\frac{1}{1+\theta} L_{t}^{1+\theta}\right) \exp \left(\lambda_{1} t+\varepsilon_{1 t}\right)\right]^{1-\gamma}
$$

where $\theta$ has the interpretation of one over the intertemporal elasticity of substitution in labor supply. This specification conforms to the main standard requirements of a utility function but it has the restrictive, although very convenient, property that the marginal rate of substitution between consumption and labor supply is independent of consumption:

$$
-\frac{U_{\ell}(t)}{U_{C}(t)}=\frac{\Phi_{2}}{\Phi_{1}} L_{t}^{\theta} \exp \left(\lambda_{1} t+\varepsilon_{1 t}\right)
$$

The implication of this property is that there are no income effects on labor supply and, hence, the model can be solved independently of the dynamic optimization over consumption. ${ }^{2}$ This is an extreme version of the presumption that substitution effects on labor supply dominate the income effects. The dependence of preferences on time generates flexibility in terms of possibly different time trends in labor input and production. The random shock yields linearly independent disturbances in the reduced forms for those two variables. The empirical formulation of the production function in equation (2) is:

$F\left(L_{t} N_{t}, K_{t}, H_{t} / G_{t}, t, \varepsilon_{2 t}\right)=F_{0}\left(L_{t} N_{t}\right){ }^{\alpha_{1} \alpha_{2}{ }^{\alpha} \alpha_{3}{ }^{\alpha}{ }_{G}^{\alpha}}{ }_{t}{ }_{t} \exp \left(\lambda_{2} t+\varepsilon_{2 t}\right), \alpha_{1}+\alpha_{2} \leq 1, \alpha_{1}+\alpha_{3} \leq 1$.

2 This property obviously holds also for $\left[U\left(C_{t}, L_{t}\right)\right]^{1 / 1-\gamma}$ of which (15) is a monotonic transformation. I preferred to use (15) in the text to stress that a constant marginal utility of consumption is not required to eliminate the income effect. 
The capital stock and the utilization rate enter with individual coefficients to allow for differential effects of the two ways of altering the capital services. The two conditions for non-increasing returns become identical when $\alpha_{2}=\alpha_{3}$

Given the process governing $\mathrm{N}_{t}$, the counterpart to the expression in equation (1') is:

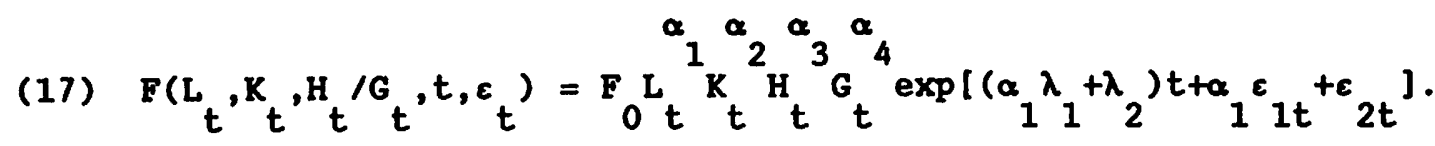

From the previous section, the two equations required to solve the model are

(12) $-\frac{U_{\ell}(t)}{U_{c}(t)}=\frac{F_{\ell}(t)}{1+r_{t}}$, and

$$
F_{h}(t)=\delta_{t} K_{t}\left(1+r_{t}\right)
$$

Under the functional forms in (15) and (17), this is a two-equation system for $L_{t}$ and $H_{t}$, given $r_{t}, G_{t}, K_{t}, t$ and the disturbances $\varepsilon_{1 t}$ and $\varepsilon_{2 t}$. Denoting the $\log$ of a variable by the corresponding lower-case letter and taking log $\left(1+r_{t}\right) \approx r_{t}$, the solution is:

$$
\begin{aligned}
& l_{t}=b_{0}+b_{1} r_{t}+b_{2} g_{t}+b_{3} k_{t}+b_{3} t+e_{2 t} \\
& h_{t}=c_{0}+c_{1} r_{t}+c_{2} g_{t}+c_{3} k_{t}+c_{4} t+e_{3 t},
\end{aligned}
$$




$$
\begin{array}{ll}
b_{1}=-(1 / \bar{a}) & c_{1}=-(1+\theta) / \bar{a} \\
b_{2}=\alpha_{4} / \bar{a} & c_{2}=\alpha_{4}(1+\theta) / \bar{a} \\
b_{3}=\left(\alpha_{2}-\alpha_{3}\right) / \bar{a} & c_{3}=-\left[(1+\theta)\left(1-\alpha_{2}\right)-\alpha_{1}\right] / \bar{a} \\
b_{4}=\left[\left(\alpha_{1}+\alpha_{3}-1\right) \lambda_{1}+\lambda_{2}\right] / \bar{a} & c_{4}=\left[\alpha_{1} \theta \lambda_{1}+(1+\theta) \lambda_{2}\right] / \bar{a} \\
e_{2 t}=\left[\left(\alpha_{1}+\alpha_{3}-1\right) \varepsilon_{1 t}+\varepsilon_{2 t}\right] / \bar{a} & e_{3 t}=\left[\alpha_{1} \theta \varepsilon_{1} t+(1+\theta) \varepsilon_{2 t}\right] / \bar{a},
\end{array}
$$

where $\bar{a}=(1+\theta)\left(1-\alpha_{3}\right)-\alpha_{1}$. Given the assumption that $\alpha_{1}+\alpha_{3} \leq 1$

and $\theta>0$, it holds that $\bar{a}>0$. Hence, the real interest rate affects labor input and capital utilization negatively. Government spending services, by increasing productivity of both inputs, have a positive effect on $l_{t}$ and $h_{t}$. The capital stock has a negative effect on $h_{t}$ since it increases the marginal utilization costs by more than it raises the marginal productivity of utilization. The effect of $k_{t}$ on labor input depends on $\alpha_{2}-\alpha_{3}$. This difference comes from the opposite movements of $\mathrm{K}_{t}$ and $\mathrm{H}_{\mathrm{t}}$ which affect labor marginal productivity in opposite directions.

Substituting (18) and (19) into the production function (expressed in logs) yields the solution for production:

$$
\begin{aligned}
& y_{t}=a_{0}+a_{1} r_{t}+a_{2} B_{t}+a_{3} k_{t}+a_{4} t+e_{1 t}, \\
& a_{1}=-\left[\alpha_{1}+\alpha_{3}(1+\theta)\right] / \bar{a} \\
& a_{2}=\alpha_{4}(1+\theta) / \bar{a} \\
& a_{3}=\left(\alpha_{2}-\alpha_{3}\right)(1+\theta) / \bar{a} \\
& a_{4}=\left[\alpha_{1} \theta \lambda_{1}+(1+\theta) \lambda_{2}\right] / \bar{a} \\
& e_{1 t}=\left[\alpha_{1} \theta \varepsilon_{1 t}+(1+\theta) \varepsilon_{2 t}\right] / \bar{a} .
\end{aligned}
$$


Both interest rate effects on labor input and capital utilization are reflected in the negative output effect. The model also predicts a (likely) procyclical movement of average labor productivity in response to real interest rate shifts. The effect on labor productivity is given by the difference $a_{1}-b_{1}$, the sign of this expression depending on $\alpha_{1}+\alpha_{3}(1+\theta)>1$. The estimated parameters will supply an answer to this question. However, it is possible to assess this inequality based on a priori considerations. MaCurdy (1981) estimates an intertemporal elasticity of substitution corresponding to $1 / \theta$ in the range of .10 to .45 , implying $\theta$ in the range 2.22-10. Hall (1980) estimates a similar elasticity as .66 , corresponding to $\theta \approx 1.5$. Since $\alpha_{1}+\alpha_{3}$ is likely to be not far below 1 , these values for $\theta$ imply that $\alpha_{1}+\alpha_{3}(1+\theta)$ is likely to be larger than one, and hence labor productivity would move procyclically. As with labor input, the coefficient of the capital stock on output depends on $\alpha_{2}-\alpha_{3}$. Finally, if $\lambda_{1}>0$, $\lambda_{2}>0,--i . e .$, if both production technology and human capital improve over time--the economy grows at the positive rate $\left[\alpha_{1} \theta \lambda_{1}+(1+\theta) \lambda_{2}\right] / \bar{a}$ per period. Recall that there is no population growth in the model. Labor input may increase or decrease since in $b_{3}, \lambda_{1}$ is multiplied by $\alpha_{1}+\alpha_{3}-1$ which can be negative. The possibility of a decline follows from the positive effect of human capital quality on the desirability of leisure.

Equations (18), (19) and (20) form a three-equation system. However, only two equations are estimated, the labor and the output equations. This is so mainly because of the nature of the capital utilization data. The available figures are based on a comparison of actual output in manufacturing 
to an estimated capacity output. ${ }^{3}$ Hence, the variation in these measures is associated by construction with the output variable to be used in the estimation of the output equation. It would not be informative, therefore, to estimate both equations at the same time using these data on capacity utilization. Note also that, given the current specification of the structural disturbances, equations (19) and (20) have identical error terms. Therefore only (19) or (20) can be simultaneously estimated with (18).

Equations (18) and (20) contain 8 reduced-form coefficients (excluding the constants which are unidentified) that are functions of the 7 structural parameters $\alpha_{1}, \alpha_{2}, \alpha_{3}, \alpha_{4}, \theta, \lambda_{1}$ and $\lambda_{2}$. Hence, there is one over-identifying restriction, which is $a_{2} / b_{2}=a_{3} / b_{3}$. Both ratios equal $1+\theta$. Wow, given that the expressions for $a_{1}$ and $b_{1}$ do not place independent restrictions on $\alpha_{1}$ and $\alpha_{3}$ (in both equations they enter as $\alpha_{1}+\alpha_{3}(1+\theta)$ ) it is not possible to disentangle all the structural parameters. It is possible, however, to identify $\alpha_{4}=-b_{2} / b_{1}$ and $\alpha_{2}-a_{3}=-a_{3} b_{2} / a_{2} b_{1}$. The variance-covariance matrix of the disturbances does not pose, in general, additional restrictions. It includes 3 restrictions for $\operatorname{Var}\left(e_{1}\right), \operatorname{Var}\left(e_{2}\right)$ and $\operatorname{Cov}\left(e_{1}, e_{2}\right)$, but at the same time it introduces 3 additional unknowns, $\operatorname{Var}\left(e_{1}\right)$, $\operatorname{Var}\left(\varepsilon_{2}\right)$ and $\operatorname{Cov}\left(\varepsilon_{1}, \varepsilon_{2}\right)$. Given the little known about the structural disturbances, it does not seem appropriate to restrict their variance-covariance matrix.

In order to test the present model formally, an alternative one should be properly defined. Given that the main feature of the present framework is the production $\mathrm{lag}$, the natural alternative is a model with the standard, within-the-period, production funtion $Q_{t}=Y_{t}=F(\ldots)$, but that is

${ }^{3}$ See "Capacity Utilization Rates in Canadian Manufacturing," Statistics Canada, Catalogue 31-003. 
otherwise identical to the present model. Under this technology, the resulting equations differ from (18)-(20) only by lacking the interest rate terms. Hence, the null hypothesis is defined as $H_{0}: a_{1}=b_{1}=0$. With a more general utility function, however, the intertemporal effect of the interest rate on labor supply could operate, so that the null hypothesis can be interpreted as $a_{1} \geq 0, b_{1} \geq 0$. The hypothesis implied by the present mechanism is $H_{1}: a_{1}<0, b_{1}<0$. Under this definition of the alternative model, the overidentifying restriction applies to both models. However, this restriction can also be tested.

\section{Estimation of Real Interest Rate Variables}

This section reports the estimation of measures of the anticipated real interest rate in the United States (considered an exogenously-given price for the Canadian economy): Since the model is estimated with annual data, the relevant interest rate variable is an annual average of this rate. The procedure adopted is to estimate the anticipated real rate with quarterly data and then to calculate the corresponding annual averages. The real rate is calculated by subtracting from a nominal interest rate an estimate of expected inflation.

Define $i_{j t}$ as the nominal interest rate in quarter $j$ of year $t$ at an annual rate. The variable used for $i_{j t}$ is the 3 -month $U . S$. Treasury bill rate because the more appropriate one-year rate is not available for the entire 1952-1984 period used. The real interest rate is then defined as:

$$
\text { (21) } \quad r_{j t}=i_{j t}-\pi_{j t}^{e} \text {, }
$$

where $\pi_{j t}^{e} \equiv E_{j+1, t} / I_{j t} ; \pi_{j+1, t}$ is the inflation rate from quarter $j$ to 
quarter $j+1$ at an annual rate and $I_{j t}$ is the information set available to agents at $j, t$. The annual average real interest rate is then

$$
r_{t}=\frac{1}{4} \sum_{j} i_{j t}-\frac{1}{4} \sum_{j} \pi_{j t}^{e} .
$$

Following a procedure similar to that in Mishkin (1981), the unobservable expectation $\pi_{j t}^{e}$ is specified to be formed as

$$
{ }_{j t}^{e}=w_{j t}^{\Psi}
$$

where $w_{j t}$ is the row vector $\left[1, i_{j t}, \ldots, i_{j-3, t}, \pi_{j t}, \ldots,{ }_{j-3, t}\right]$ and $\psi$ is a corresponding vector of coefficients. Given the definition of $\pi_{j t}^{e}$, the actual inflation rate satisfies

$$
\pi_{j+1, t}={ }_{j t}^{e}+u_{j+1, t} \text {, }
$$

where $E\left(u_{j+1, t} / I_{j t}\right)=0$. Combining (22) and (23) yields

$$
\pi_{j+1, t}=w_{j t} \psi+u_{j+1, t} .
$$

Since $\pi_{j+1, t}$ and $w_{j t}$ are observable and $u_{j+1, t}$ is by construction white noise and orthogonal to $w_{j t}$, this equation can be consistently and efficiently estimated by oLs. The specification of (22) implies that the current and the 3 lagged values of the nominal interest and inflation rates capture all information used by agents in their linear forecast of the next quarter's inflation rate. An error term could be included in (22) to capture other relevant information, orthogonal to the $i^{\prime} s$ and $\pi^{\prime} s$, and then the disturbance in (24) would be a composite one. However the variance of such an error term is presumed to be small relative to the variance of $u_{t+1}$ and hence it is neglected. 
Using the coefficients from estimating (24) in (22) yields

$\tilde{\pi}_{j t}^{e}=w_{j t} \dot{\psi}$. The corresponding estimate of the quarterly real interest rate at an annual rate is

(21') $\quad \hat{\mathbf{r}}_{\mathbf{j t}}=\mathbf{i}_{\mathbf{j t}}-w_{\mathbf{j} t \hat{\psi}}$,

and the annual average follows as

$$
\hat{\mathbf{r}}_{t}=\mathbf{i}_{t}-w_{t} \hat{\psi}
$$

where $i_{t}$ is the annual average nominal interest rate and $w_{t}=\frac{1}{4} \sum_{j} w_{j t}$.

Similarly as in Mishkin (1981) the deviation of the estimate $\hat{r}_{t}$ around the true $r_{t}$ is calculated as

$$
r_{t}-\hat{r}_{t}=\hat{\pi}_{t}^{e}-\tilde{\pi}_{t}^{e}=w_{t} \dot{\psi}-w_{t} \psi \text {. }
$$

Using the form of the oLS estimator this error can be expressed as

$$
r_{t}-\hat{r}_{t}=w_{t}\left(w^{\prime} \cdot\right)^{-1} w^{\prime} u
$$

where $\mathrm{W}$ is the matrix having the ${ }^{{ }_{j t}}{ }^{\text {'s }}$ as rows and $\mathrm{u}$ is the column vector with the $u_{j+1, t}$ 's as components. The variance of $r_{t}-\hat{r}_{t}$ is then

$$
\left.\operatorname{var}\left(r_{t}-\hat{r}_{t}\right)=\sigma_{u^{\prime} w_{t}}^{2}\left(w^{\prime} w^{-1}\right)^{\prime} w^{\prime} w^{\prime} w^{\prime} w^{-1}\right)^{\prime} w_{t}=\sigma_{u^{\prime}} w_{t}\left(w^{\prime} w^{\prime}\right)^{-1} w_{t}^{\prime} .
$$

The value of $\sigma_{u}^{2}$ is estimated from equation (24)and the quadratic form in (25) can then be calculated. It is used below to assess the implications of the use of $\hat{r}_{t}$ in the estimation in place of the unobservable $r_{t}$.

Two price indexes were used to construct ${ }^{\natural}{ }^{e} j t$, the Producer Price Index (PPI) and the Consumer Price Index (CPI) less shelter. The PPI has the 
advantage that it better reflects prices of internationally tradable goods and hence is probably more appropriate to measure the real interest rate in the international capital market. However, it has the drawback that it does not always include discounts from list prices. The CPI-less-shelter index does not have this problem and it is used to check the sensitivity of the results. The sample used to estimate equation (24) is $1952: 2$ 1985:1, which yields $\pi^{0} j t$ for 1952:1 1984:4 and annual averages for 1952-1984. If the period is extended backwards to include 1951 or 1950 and 1951 the goodness-of-fit materially worsens. Apparently, this is so because of the out-of-line, high inflation rates in 1950 and the first quarter of 1951 . Almost no change in the goodness-of-fit occurs when the sample is shortened to 1953.

Estimates of equation (24) are reported in Table 1 and the calculated annual averages $\hat{\mathbf{r}}_{t}$ in Table 3 . The values for $\hat{\mathbf{r}}_{\mathrm{PPI}}$ have quite an impressive variation during the sample. They range from about $-9 \%$ in 1974 to about $10 \%$ in 1982. The variation in $\hat{\mathbf{r}}_{\mathrm{CPI}}$ is not quite as dramatic, but it follows a similar pattern.

\section{v. 'User Cost' and the Capital Stock Data}

The net capital stock figures published by Statistics Canada are constructed using the Perpetual Inventory Method and a linear depreciation scheme. ${ }^{4}$ This form of calculating depreciation presents a problem in this context since the model used here involves the notion of 'user cost'. This implies a positive association between the extent to which capital is used and its physical deterioration. In order to avoid an inconsistency between the

\footnotetext{
"Fixed Capital Flows and Stocks," Statistics Canada, Catalogue 13-568.
} 
way the data are constructed and a basic premise of the model, the capital stock figures for the aggregate economy were recalculated to incorporate this view of depreciation. 5

In the present model, the net capital stock is postulated to evolve according to

$$
K_{t+1}=\left(1-\delta H_{t}\right) K_{t}+I_{t}
$$

In general, the procedure followed here consists, first, in obtaining measures of $H_{t}$ and an estimate of $\delta$. Then, a new series of $K_{t}$ is constructed from an initial value $k_{0}$ and data on gross investment. What is done here is, hence, an adjustment of the Perpetual Inventory Method to account for a dependence of the 'average' depreciation rate of the aggregate capital stock on an aggregate measure of utilization. "The series was calculated for the 1935-1984 period. An early starting point was required to eliminate most of the weight of the initial $K_{0}$ value in the figures corresponding to the 1952-84 sample, used in the tests.

The first step is to obtain measures of $\mathrm{H}_{t}$. Following the standard procedure, capacity utilization rates were derived from the comparison of actual production levels to a benchmark of capacity output. This procedure, although still problematic, seems to be a satisfactory approximation for the present purposes. Since the published figures on utilization rates start in

${ }^{5}$ I thank Michael Parkin for suggesting the form of the present calculation. Any shortcomings in its implementation are, of course, mine.

${ }^{6}$ Undoubtedly a preferable procedure would be to apply a similar method to the individual capital assets and then to aggregate. This is obviously a much more demanding task which is probably useful to attempt. 
1961, there is a need to construct new ones to have a consistent series from 1935. The new series is estimated using the percentage deviations of GNP from an exponential trend, translating these deviations to $H_{t}$ figures by assigning the value of 1.00 to the largest positive one.

The parameter $\delta$ is then estimated as follows. The capital evolution equation can be rewritten as

$$
K_{t+1}=\left(1-d_{t}\right) K_{t}+I_{t}
$$

Using this equation and the published data on the net capital stock and gross investment, it is possible to calculate the average depreciation rate $d_{t}$ implied in the published net stock series, for each year in the sample. (The procedure used in the construction of these data allows for different service lives and hence different depreciation rates of individual components.) Assuming the depreciation scheme adopted by statistics Canada is correct in the long-run average (although it does not capture the cyclical variations in depreciation), the average value of $d_{t}$ corresponds to the average value of $\delta H_{t}$. Hence, the estimate $\hat{\delta}=\Sigma d_{t} / \Sigma H_{t}$ can be obtained. Then, using $k_{0}, \hat{\delta}$, and the figures for $H_{t}$ and $I_{t}$, the entire new series is constructed.

Data used in these calculations are the end-of-year net stock of fixed non-residential capital in manufacturing and non-manufacturing industries in constant 1971 prices, and the corresponding gross fixed capital formation. The average value of $d_{t}$ in the $1935-1984$ period is .052 , with very little variation. Real GNP in 1971 prices was used to estimate an exponential trend over the 1935-84 sample. The largest positive deviation corresponds to 1942 (.17), taken as the year of $H=1$. The initial $\mathrm{K}_{0}$ for 1935 is the figure 
published in the original series. The $\hat{\delta}$ estimate obtained is .062 , which is interpreted as the depreciation corresponding to $\mathrm{H}=1$. Compared to the published series, the new values for $\mathrm{k}_{t}$ tend, as expected, to have lower values during periods of above trend output and higher values in the opposite cases. The calculated figures, along with the published ones for comparison, are reported in Table 3 .

VI. Estimation

The model is estimated using annual Canadian data. The Canadian economy is especially interesting in this context because it seems that it can be satisfactorily characterized as a competitive open economy, a price-taker in the international capital market and not subject to capital controls.

Production is measured by an index of Gross Domestic Product in Canada at constant 1971 prices, labor input is an index of the man-hours worked of paid workers in the domestic economy and the government spending variable is government expenditure on goods and services in constant 1971 prices. The capital stock data are as reported in section $v$. Since the model does not accommodate population growth, the output, labor input, government spending and the capital stock variables are divided by the population over 15 years of age. The data were obtained from the Cansim Data Retrieval of statistics Canada and are as reported in Table 3.

The model is estimated in a two-step procedure. The series $\mathbf{r}_{t}$ ' constructed first, is used in the estimation of equations (18) and (20). Given the error in the measurement of the interest rate variable in the first step, the equations to be estimated are now ${ }^{7}$

7 Errors in measurement in the capital stock and other variables are neglected. Hopefully, they are not important. 
(20') $y_{t}=a_{0}+a_{1} \hat{r}_{t}+a_{2} b_{t}+a_{3} k_{t}+a_{3} t+a_{1} \xi_{t}+e_{1 t}$

(18')

$$
\ell_{t}=b_{0}+b_{1} \hat{r}_{t}+b_{2} g_{t}+b_{3} k_{t}+b_{3} t+b_{1} \xi_{t}+e_{2 t} \text {. }
$$

where $\xi_{t}=\hat{r}_{t}-r_{t}$. The error $\xi_{t}$ is uncorrelated by construction with $\hat{r}_{t}$ and by assumption with $g_{t}, k_{t}, t, e_{1 t}$ and $e_{2 t}$ Also, $g_{t}, k_{t}$ and $t$ are assumed irrelevant for the prediction of the U.S. real interest rate. As Pagan (1984) showed in a general context of this type, the present two-step procedure is efficient and the standard errors from the second step yield correct inferences for the hypothesis $a_{1}=b_{1}=0$.

$$
\text { If } a_{1} \neq 0, b_{1} \neq 0 \text { the model has composite disturbances. It is }
$$
possible, however, to assess in a rough manner the relative importance of the two components. The variances of the two composite disturbances are

$$
\begin{aligned}
& \operatorname{Var}\left(a_{1} \xi_{t}+e_{1 t}\right)=a_{1}^{2} \operatorname{Var}\left(\xi_{t}\right)+\operatorname{Var}\left(e_{1}\right) \\
& \operatorname{Var}\left(b_{1} \xi_{t}+e_{2 t}\right)=b_{1}^{2} \operatorname{Var}\left(\xi_{t}\right)+\operatorname{Var}\left(e_{2}\right)
\end{aligned}
$$

The variances on the left-hand side correspond to the variances of the regressions of $\left(20^{\prime}\right)$ and (18') which also yield estimates of $a_{1}$ and $b_{1}$. From equation (25), $\operatorname{var}\left(\xi_{t}\right)=\sigma_{u}^{2} w_{t}\left(w^{\prime} w^{-1} w_{t}^{\prime}\right.$, which can be estimated as described previously. Hence, the magnitudes of the ratios $a_{1}^{2} \operatorname{Var}\left(\xi_{t}\right) / \operatorname{Var}\left(e_{1}\right)$ and $b_{1}^{2} \operatorname{Var}\left(\xi_{t}\right) / \operatorname{Var}\left(e_{2}\right)$ can be evaluated. Using the averages of $\operatorname{Var}\left(\xi_{t}\right)$ over the sample, the values calculated for the first ratio are $2.2 \%$ and $1.0 \%$, using the PPI and the CPI respectively, and $1.1 \%$ and $0.3 \%$ for the second ratio. 8

${ }^{8}$ These values should be considered lower bounds only, if additional variables are used by agents in the formation of $\pi_{j}^{e}$ in equation (23). However, as discussed by Mishkin (1981) this seems unlikely to be a quantitiatively serious consideration. The values used in the calculation 
Given these small values, it seems that neglecting $a_{1} \xi_{t}$ and $b_{1} \xi_{t}$ in the treatment of the disturbances may be a reasonable approximation.

Given extremely strong correlation of the time trend with the capital stock (correlation coefficient of 0.99 ) and to a lesser extent with government spending, the model cannot be satisfactorily estimated in the original form of equations (18) and (20). Hence, all relevant variables were detrended prior to the estimation, to eliminate the time variable. This procedure does not alter the identification of the rest of the model because it eliminates two reduced-form parameters and two structural coefficients. The trends used were estimated over the 1952-1984 sample and they are 0.022 for $y_{t}, 0.0006$ for $\ell_{t}$ ' 0.018 for $g_{t}$ and 0.028 for $k_{t}$ (all variables in $10 g$ of per capita terms). The theory does not have anything to say about the time-series properties of the residuals $e_{1 t}$ and $e_{2 t}$. The specification chosen for these disturbances is first-order Markov processes with coefficients $\boldsymbol{p}_{1}$ and $\boldsymbol{p}_{2}$ respectively. Note that in this case joint estimation of (18) and (20) can improve efficiency despite the fact that both equations contain identical sets of explanatory variables. This is so because the transformation of the equations to eliminate the serial correlation breaks the similarity between the two sets of regressors. Simultaneous estimation is also necessary to impose the cross-equation restriction.

are the following. Using the PPI, the average Varr $\left(\xi_{t}\right)$ in the sample is $.52 \times 10^{-4}$. From results reported below in $(26 a, b) \hat{a}_{1}=-.50, \hat{b}_{1}=-.27$, and from the estimates of $\sigma, p_{1}$ and $p_{2}$ it follows that $\hat{\operatorname{var}}\left(a_{1} \xi_{t}+e_{1}\right)=$ $6.0 \times 10$ and $\operatorname{var}\left(b_{1} \xi_{t}+e_{2}\right)=3.6 \times 10^{-4}$. For the $C P I$, the average value of $\operatorname{var}\left(\xi_{t}\right.$ ) is $0.1 \times 10^{-4}$, and from Table 2 (rows $3-4$ ), $\hat{a}_{1}=-.82$, $\hat{b}_{1}=-.35, \operatorname{Var}\left(a_{1} \xi_{t}+e_{1}\right)=6.5 \times 10^{-4}$ and $\operatorname{var}\left(b_{1} \xi_{t}+e_{2}\right)=3.8 \times 10^{-4}$. 
The system was estimated by maximum likelihood using $\hat{\mathbf{r}}_{\mathrm{PPI}}$, calculated with the PPI, and then with $\hat{r}_{\text {CPI }}$, corresponding to the CPI-less-shelter. The equations with $\hat{\mathbf{r}}_{\mathrm{PPI}}$ are

$$
\begin{aligned}
& \text { (26a) } y_{t}=.007-.50 \hat{r}_{P P I, t}+.41 g_{t}+.50 k_{t} \\
& \begin{array}{lll}
(.006)(.15) \quad(.08) \quad(.18)
\end{array} \\
& \begin{array}{lll}
\hat{\sigma}_{1}=.0237 & \text { D.W. }=1.68 & \hat{p}_{1}=.26
\end{array} \\
& \text { (.13) } \\
& \text { (26b) } \ell_{t}=.003-.27 \hat{r}_{P P I, t}+.09 g_{t}-.10 k_{t} \\
& (.006)(.11) \quad(.07) \\
& \begin{array}{lll}
\hat{\sigma}_{2}=.0164 & \text { D.W. }=1.76 & \hat{p}_{2}=\begin{array}{l}
.509 \\
(.13)
\end{array}
\end{array}
\end{aligned}
$$

Sample: 1953-1984,

where the standard errors appear below the corresponding estimates.

The coefficients of main interest are those of $\hat{\mathbf{r}}$. The point estimates indicate that a one percentage point increase in the real interest rate reduces output by half of a percent, and labor input by $.27 \%$. The corresponding effect on average labor productivity is procyclical with a . $23 \%$

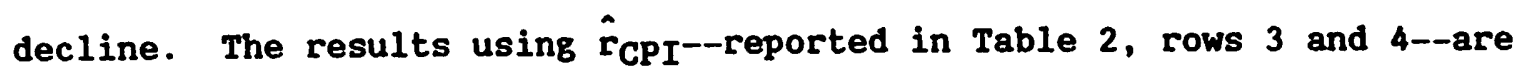
qualitatively similar, but the magnitudes of the interest rate effects are larger: $-.82 \%$ for output, $-.35 \%$ for labor input and $-.47 \%$ for productivity.

${ }^{9}$ The statistics $\hat{\sigma}$ and D.W. correspond to the transformed data. Hence, for the calculation referred to in foonote $(8)$, the variances of the untransformed residuals were calculated as $\hat{\sigma}_{1}^{2} /\left(1-\hat{\rho}_{1}^{2}\right)$ and $\hat{\sigma}_{2}^{2} /\left(1-\hat{\rho}_{2}^{2}\right)$. 
Apparently, the source of this difference is the wider variation in $\hat{\mathbf{r}}_{\mathrm{PPI}}$. The standard deviation of $\hat{r}_{\text {PPI }}$ over the sample is $3.6 \%$ and that of $\hat{r}_{\mathbf{C P I}}$ is 2\%. However, higher variation cannot be attributed to additional noise, because the $\hat{\sigma}$ values in the equations with $\hat{r}_{\text {PPI }}$ are somewhat smaller than with $\hat{\mathbf{r}}_{\text {CPI. }}$

The coefficient of $k_{t}$ in the labor equation follows from the constraint $a_{2} / b_{2}=a_{3} / b_{3}=1+\theta$. The likelihood-ratio test of this constraint produced the statistic $0.8(-2 \log$ (1ikelihood ratio)), which is asymptotically distributed $x^{2}$ with one degree of freedom. Since the $5 \%$ critical value is 3.8 the restriction cannot be rejected. The unconstrained equations are reported in Table 2, rows 5-8. The corresponding estimate of $\theta$ is 3.8 or 0.26 for $1 / \theta$ (3.25 and 0.31 with $\left.\hat{r}_{C P I}\right)$. These values of $1 / \theta$ are lower than the .66 estimate of a corresponding coefficient obtained by Hall (1980) and fall within the .10-.45 range obtained by MaCurdy (1981). The estimate of $\alpha_{4}$ is .32 (.27 with $\hat{\mathbf{r}}_{\mathrm{CPI}}$ ) and that of $\alpha_{2}-\alpha_{3}$ is .39 (.31 with $\hat{\mathbf{r}}_{\mathrm{CPI}}$ ). These values seem too high and they cast some doubt over the specification of the model. It should be noted, however, that all these estimates are not very reliable because they are based on the coefficient of $\mathrm{g}_{t}$ in the labor equation which is imprecisely estimated.

The null hypothesis to be tested is $H_{0}: a_{1}=b_{1}=0$, which can be tested using the likelihood-ratio test of these two constraints. Note that the test is too conservative since it involves a two-sided alternative, while the hypothesis developed from the model is one-sided. The -2 log (likelihoodratio) value for $a_{1}=b_{1}=0$ is 8.7 ( 8.8 when $\hat{r}_{C P I}$ is used) and the $5 \%$ critical value corresponding to the $x^{2}$ distribution with 2 df is 5.99 . Hence, 
the null hypothesis is rejected. Similar results are obtained when the test is applied to the unconstrained equations (Table 2, rows 5-8). The test statistic is 6.8 and 7.2 with $\hat{r}_{\mathrm{CPI}}$.

By looking at the $\hat{\mathbf{r}}_{\mathrm{PPI}}$ and $\hat{\mathbf{r}}_{\mathrm{CPI}}$ series, reported in Table 3 , it can be noted that the values corresponding to 1981-1984 are unusually high. The values of $\hat{r}_{\text {CPI }}$ in these years range from $6.7 \%$ to $10.5 \%$--after a $.7 \%$ level in 1980 . For $\hat{r}_{\text {CPI }}$, the increase is somewhat less dramatic but still very pronounced. At the same time output and labor input per capita are strongly below trend. Hence, a relevant sensitivity test is the reestimation of the equations excluding these observations to see to what extent the results shown above depend on them. The resulting estimates are reported in Table 2, rows 9 and 10 (rows 11 and 12 with $\hat{r}_{\text {CPI }}$ ). The negative effects of the real interest rate on output and labor input are still present but the magnitudes and the significance levels are lower.

Using the $\log -1$ ikelihood ratio test, the constraints $a_{1}=b_{1}=0$ cannot be rejected now. The test statistic obtained is 3.6 ( 4.8 with $\hat{r}_{\text {CPI }}$ ), below the 5.99 critical value. However, the coefficients of the real interest rate in the output equation are still significant, both statistically and quantitatively. The value of $\hat{a}_{1}$ is .39 , with a t-value of 2.1 (.82 and 2.1 with $\hat{r}_{\text {CPI }}$ ). Although the 1981-1984 observations indeed seem important for the results reported above, the effect under study can also be detected in the shorter sample.

\section{vII. Concluding Remarks}

This paper addresses the effects of the anticipated real interest rate on aggregate supply variables in a model with a production lag and endogenous 
capacity utilization. The potential importance of the mechanism studied here for business cycle theory lies in its ability to generate co-movements in macroeconomic variables that correspond to those usually observed in business cycles. In response to real interest movements the model predicts a positive co-movement of employment, capacity utilization, investment and output. Labor productivity is also likely to move procyclically.

The model is tested with Canadian data, taking the exogenous real interest rate as that prevailing in the United States. Measures of the real interest rate were constructed by subtracting estimates of expected inflation from the 3-month U.S. Treasury bill yield. Two alternative price indexes were used, the Producer Price Index and the Consumer Price Index-less-shelter. The empirical tests provide support for the main implications of the model. However, it seems that more research in this area is needed to ascertain its empirical importance. The strength of the results turns out to be sensitive to the sample period. When the 1981-1984 observations are deleted from the 1953-1984 sample, the negative real interest rate effects appear weaker. It is possible that omitted considerations like energy prices may be relatively more important in the pre-1981 period. The introduction of energy input interacting with the variable capacity utilization and labor input within the time-to-produce framework seems to be a relevant extension of the present model. 


\section{References}

Ahmed, S., "Temporary and Permanent Government Spending in an Open Economy: Some Evidence for the U.K.," Brown University Working Paper No. 85-13, forthcoming in the Journal of Konetary Economics.

Barro, R.J., "Intertemporal Substitution and the Business Cycle," Carnegie-Rochester Conference Series on Public Policy, Spring 1981(a). - "Output Effects of Government Purchases," Journal of Political Economy, December 1981(b). and R.G. King, "Time-Separable Preferences and Intertemporal Substitution Models of the Business Cycle," The Quarterly Journal of Economics, November 1984.

Böhm-Bawerk, V., The Positive Theory of Capital, New York, 1923.

Carlton, D.W., "Contracts, Price Rigidity, and Market Equilibrium," Journal of Political Economy, 1979.

Grossman, S. J., and L. Weiss, "Heterogeneous Information and the Theory of the Business Cycle," Journal of Political Economy, August 1982.

Ha11, R.E., "Labor Supply and Aggregate Fluctuations," Carnegie-Rochester Conference Series on Public Policy, Spring 1980.

Heckman, J. J., "A Life-Cycle Model of Earnings, Learning and Consumption," Journal of Political Economy, August 1976, Part 2.

King, R.G., "Money, Real Wages and the Business Cycle," University of Rochester, September 1980.

Kydland, F.E. and E.C. Prescott, "Time-to-Build and Aggregate Fluctuations," Econometrica, November 1982.

Long, J. B. and C. I. Plosser, "Real Business Cycles," Journal of Political Economy, February 1983. 
Lucas, R.E. and L.A. Rapping, "Real Wages, Employment and Inflation," Journal of Political Economy, September/October 1969.

MaCurdy, T. E., "An Empirical Model of Labor Supply in a Life-Cycle Setting," Journal of Political Bconomy, December 1981.

Merrick, J.J., "The Anticipated Real Interest Rate, Capital Utilization and the Cyclical Pattern of Real Wages," Journal of Monetary Bconomics, January 1984 .

Mi11, J.S., Principles of Political Economy, London, New York, 1909.

Mishkin, F. S., "The Real Interest Rate: An Empirical Investigation," Carnegie-Rochester Conference Series on Public Policy, Autumn 1981.

Pagan, A. R., "Econometric Issues in the Analysis of Regressions with Generated Regressors," International Bconomic Review, February 1984.

Statistics Canada, "Fixed Capital Flows and Stocks," Catalogue 13-568.

Statistics Canada, "Capacity Utilization Rates in Manufacturing," Catalogue 31-003.

Taubman, P. and M. Wilkinson, "User Cost, Output and Unexpected Price Change," in Edmund Phelps, ed., Microeconomic Foundations of Employment and Inflation Theory, New York, 1970. 


\section{TABLE 1}

\section{U.S. Inflation Forecast Equation}

Producer Price Index

$$
\begin{aligned}
& \text { (1) } \pi_{j+1, t}=.013+.36 \pi_{j t}+.19 \pi_{j-1, t}+.03 \pi_{j-2, t}+.30 \pi_{j-3, t} \\
& \begin{array}{llll}
(.007) & (.09) \quad(.09) \quad(.09) \quad(.09)
\end{array} \\
& \begin{array}{c}
-.02 i_{j t}+.81 i_{j-1, t}-{ }_{j-2, t}^{1.29 i}+{ }_{j-3, t}^{.36 i} \\
(.48) \quad(.69) \quad(.69)
\end{array} \\
& \mathrm{R}^{2}=.53 \quad \hat{\sigma}=.0417 \\
& \text { Sample: } 1952: 2-1985: 1
\end{aligned}
$$

CPI Less Shelter

$$
\begin{aligned}
& \text { (2) } \pi_{j+1, t}=0.005+.57 \pi_{j, t}-.17 \pi_{j-1, t}+.43 \pi \pi_{j-2, t}+.09 \pi \pi_{j-3, t} \\
& \begin{array}{llll}
(0.003)(.09) & (.09) \quad(.09) \quad(.08)
\end{array}
\end{aligned}
$$

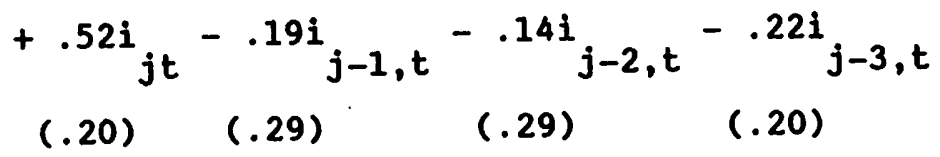

$$
\begin{aligned}
& \mathrm{R}^{2}=.77 \quad \hat{\sigma}=.0178 \\
& \text { Sample: } 1952: 2-1985: 1
\end{aligned}
$$

Notes:

$\pi_{j t}: \quad$ Inflation rate from quarter $j-1$ to quarter $j$, year $t$ at annual rates. Source: Bureau of Labor Statistics, U.S. Department of Labor.

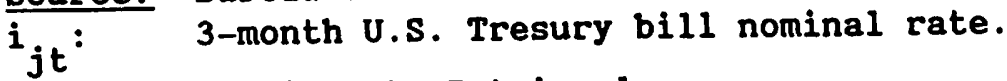

Source: Cansim Data Retrieval. 
TABLE 2

Interest

Rate Dep.

Measure variable Const. $\hat{r}_{t} \quad g_{t} \quad k_{t} \quad \hat{\rho} \quad$ D.W. $\hat{\sigma}$ Sample

\begin{tabular}{|c|c|c|c|c|c|c|c|c|c|c|}
\hline \multirow[t]{2}{*}{1} & $\hat{\mathbf{r}}_{\mathrm{PPI}}$ & $y_{t}$ & .007 & -.50 & .41 & .50 & .26 & 1.68 & .0237 & $1953-84$ \\
\hline & & & $(.006)$ & $(.15)$ & $(.08)$ & $(.18)$ & $(.13)$ & & & \\
\hline \multirow[t]{2}{*}{2} & & $l_{t}$ & .003 & -.27 & .09 & .10 & .50 & 1.76 & .0164 & \\
\hline & & & $(.006)$ & $(.12)$ & $(.07)$ & & $(.13)$ & & & \\
\hline \multirow[t]{2}{*}{3} & $\hat{r}_{C P I}$ & $y_{t}$ & .011 & -.82 & .41 & .47 & .23 & 1.70 & .0249 & \\
\hline & & & $(.007)$ & $(.27)$ & $(.08)$ & $(.17)$ & $(.12)$ & & & \\
\hline \multirow[t]{2}{*}{4} & & $\ell_{t}$ & .004 & -.35 & .10 & .11 & .49 & 1.77 & .0170 & \\
\hline & & & $(.007)$ & $(.21)$ & $(.07)$ & & $(.12)$ & & & \\
\hline \multirow[t]{2}{*}{5} & $\hat{\mathbf{r}}_{\mathrm{PPI}}$ & $y_{t}$ & .007 & -.46 & .44 & .35 & .29 & 1.68 & .0238 & \\
\hline & & & $(.006)$ & $(.15)$ & $(.08)$ & $(.24)$ & $(.13)$ & & & \\
\hline \multirow[t]{2}{*}{6} & & $e_{t}$ & .003 & -.24 & .10 & -.12 & .54 & 1.77 & .0162 & \\
\hline & & & $(.007)$ & $(.12)$ & $(.07)$ & $(.26)$ & $(.14)$ & & & \\
\hline \multirow[t]{2}{*}{7} & $\hat{\mathbf{r}}_{C P I}$ & $y_{t}$ & .011 & -.78 & .44 & .29 & .26 & 1.71 & .0247 & \\
\hline & & & $(.008)$ & $(.27)$ & $(.08)$ & $(.23)$ & $(.12)$ & & & \\
\hline \multirow[t]{2}{*}{8} & & $e_{t}$ & .005 & -.33 & .11 & -.14 & .53 & 1.79 & .0167 & \\
\hline & & & $(.007)$ & $(.21)$ & $(.07)$ & $(.26)$ & $(.13)$ & & & \\
\hline \multirow[t]{2}{*}{9} & $\hat{\mathbf{r}}_{\mathrm{PPI}}$ & $\mathbf{y}_{\mathbf{t}}$ & .009 & -.39 & .38 & .42 & .27 & 1.58 & .0224 & $1953-80$ \\
\hline & & & $(.006)$ & $(.19)$ & $(.08)$ & $(.20)$ & $(.14)$ & & & \\
\hline \multirow[t]{2}{*}{10} & & $\ell_{t}$ & .004 & -.21 & .06 & .07 & .55 & 1.70 & .0150 & \\
\hline & & & $(.006)$ & $(.13)$ & $(.07)$ & & $(.13)$ & & & \\
\hline \multirow[t]{2}{*}{11} & $\hat{\mathbf{r}}_{\mathrm{CPI}}$ & $y_{t}$ & .012 & -.82 & .39 & .48 & .17 & 1.54 & .0241 & \\
\hline & & & $(.006)$ & $(.40)$ & $(.07)$ & $(.17)$ & $(.13)$ & & & \\
\hline \multirow[t]{2}{*}{12} & & $\ell_{t}$ & .004 & -.17 & .07 & .09 & .54 & 1.64 & .0157 & \\
\hline & & & $(.007)$ & $(.28)$ & $(.07)$ & & $(.12)$ & & & \\
\hline
\end{tabular}

Standard errors are in parenthesis below the corresponding estimates. The variables $y_{t}, \ell_{t}, g_{t}$ and $k_{t}$ are detrended logs of the corresponding per-capita values. See section vr. 
TABLE 3

\begin{tabular}{|c|c|c|c|}
\hline & $\mathbf{Y}$ & L & $\mathbf{G}$ \\
\hline 52 & 63.3 & 101.1 & 861.9 \\
\hline 53 & 64.5 & 100.8 & 870.1 \\
\hline 54 & 62.2 & 97.8 & 817.9 \\
\hline 55 & 67.3 & 98.5 & 819.6 \\
\hline 56 & 71.8 & 102.3 & 825.0 \\
\hline 57 & 70.1 & 101.3 & 789.7 \\
\hline 58 & 69.8 & 97.8 & 796.3 \\
\hline 59 & 72.0 & 99.3 & 774.1 \\
\hline 60 & 72.3 & 98.6 & 778.5 \\
\hline 61 & 72.5 & 97.1 & 871.2 \\
\hline 62 & 76.2 & 98.7 & 889.0 \\
\hline 63 & 78.9 & 99.2 & 884.7 \\
\hline 64 & 82.4 & 101.2 & 909.7 \\
\hline 65 & 86.4 & 103.5 & 936.2 \\
\hline 66 & 89.9 & 104.4 & 997.4 \\
\hline 67 & 90.6 & 104.6 & 1040.0 \\
\hline 68 & 93.3 & 102.2 & 1090.9 \\
\hline 69 & 96.6 & 102.7 & 1103.7 \\
\hline 70 & 96.6 & 100.9 & 1189.1 \\
\hline 71 & 100.0 & 100.0 & 1209.5 \\
\hline 72 & 103.7 & 101.4 & 1220.1 \\
\hline 73 & 109.3 & 104.0 & 1248.1 \\
\hline 74 & 111.3 & 105.5 & 1264.8 \\
\hline 75 & 109.5 & 103.8 & 1281.9 \\
\hline 76 & 112.5 & 102.6 & 1263.3 \\
\hline 77 & 113.1 & 101.1 & 1276.7 \\
\hline 78 & 114.6 & 102.0 & 1272.4 \\
\hline 79 & 116.9 & 103.1 & 1253.4 \\
\hline 80 & 116.0 & 103.3 & 1238.4 \\
\hline 81 & 117.1 & 103.5 & 1222.3 \\
\hline 82 & 110.3 & 97.7 & 1231.6 \\
\hline 83 & 111.7 & 96.9 & 1217.8 \\
\hline 84 & 115.6 & 98.2 & 1237.1 \\
\hline
\end{tabular}

$Y_{t}$ : Canada. Index of GDP (Constant 1971 prices) per member of the 15t population.

$\mathrm{L}_{t}$ : Canada. Index of Man-hours worked of paid workers per member of the $15+$ population.

$G_{t}$ : Canada. Government Current Expenditure on Goods and Services (Constant 1971 prices) per member of the 15+ population.

Source: Cansim Data Retrieval. Statistics Canada. 
TABLE 3

(continued)

\begin{tabular}{|c|c|c|c|c|c|}
\hline & $\mathbf{i}$ & $\overbrace{\pi P P I}^{e}$ & $\stackrel{a}{\pi_{C P I}}$ & $\hat{r_{\text {PPI }}}$ & $\hat{r}_{C P I}$ \\
\hline 52 & 1.77 & -1.24 & 1.68 & 3.01 & 0.09 \\
\hline 53 & 1.94 & -0.11 & 0.77 & 2.05 & 1.17 \\
\hline 54 & 0.95 & 1.03 & -0.09 & -0.08 & 1.04 \\
\hline 55 & 1.75 & 1.77 & 0.44 & -0.03 & 1.31 \\
\hline 56 & 2.66 & 3.78 & 2.21 & -1.12 & 0.45 \\
\hline 57 & 3.26 & 3.44 & 3.40 & -0.17 & -0.13 \\
\hline 58 & 1.84 & 1.87 & 2.68 & -0.03 & -0.84 \\
\hline 59 & 3.41 & 1.15 & 1.63 & 2.26 & 1.78 \\
\hline 60 & 2.95 & 0.70 & 1.49 & 2.25 & 1.47 \\
\hline 61 & 2.38 & 0.78 & 1.11 & 1.60 & 1.27 \\
\hline 62 & 2.78 & 1.15 & 1.74 & 1.63 & 1.04 \\
\hline 63 & 3.16 & 0.64 & 1.53 & 2.51 & 1.62 \\
\hline 64 & 3.55 & 0.97 & 1.54 & 2.58 & 2.01 \\
\hline 65 & 3.95 & 2.48 & 2.03 & 1.47 & 1.92 \\
\hline 66 & 4.88 & 3.60 & 3.41 & 1.28 & 1.47 \\
\hline 67 & 4.33 & 0.83 & 2.53 & 3.50 & 1.80 \\
\hline 68 & 5.35 & 2.72 & 4.44 & 2.63 & 0.91 \\
\hline 69 & 6.69 & 4.12 & 5.12 & 2.56 & 1.57 \\
\hline 70 & 6.44 & 3.13 & 4.51 & 3.30 & 1.93 \\
\hline 71 & 4.34 & 3.41 & 3.55 & 0.93 & 0.78 \\
\hline 72 & 4.07 & 4.63 & 3.18 & -0.56 & 0.89 \\
\hline 73 & 7.02 & 12.48 & 7.76 & -5.45 & -0.74 \\
\hline 74 & 7.87 & 17.13 & 10.83 & -9.26 & -2.96 \\
\hline 75 & 5.82 & 7.78 & 7.25 & -1.95 & -1.43 \\
\hline 76 & 5.00 & 4.15 & 5.23 & 0.85 & -0.23 \\
\hline 77 & 5.27 & 5.86 & 6.40 & -0.59 & -1.13 \\
\hline 78 & 7.22 & 7.61 & 7.33 & -0.39 & -0.11 \\
\hline 79 & 10.04 & 11.33 & 10.37 & -1.28 & -0.32 \\
\hline 80 & 11.61 & 11.64 & 10.98 & -0.03 & 0.64 \\
\hline 81 & 14.08 & 7.34 & 9.09 & 6.74 & 4.99 \\
\hline 82 & 10.89 & 0.39 & 3.80 & 10.50 & 7.09 \\
\hline 83 & 8.62 & 1.42 & 3.56 & 7.20 & 5.06 \\
\hline 84 & 9.57 & 1.78 & 4.02 & 7.79 & 5.56 \\
\hline
\end{tabular}

$i_{t}: \quad$ U.S.--3-month Treasury Bill nominal yield.

e

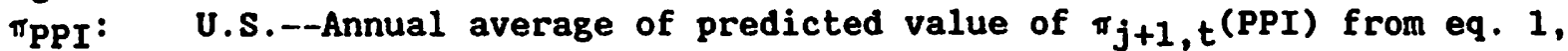
Table 1.

e

"CPI: U.S.--Annual average of predicted value of $\pi_{j+1, t}$ (CPI-less shelter) from eq. 2, Table 1 .

$\hat{r}_{\text {PPI }}: \quad i_{t}-\boldsymbol{i}_{\text {PPI }}$.

$\mathbf{r}_{\text {CPI }}: \quad i_{t}-\stackrel{e}{\pi_{C P I}}$. 
TABLE 3

(continued)

\begin{tabular}{|c|c|c|c|}
\hline & $\mathbf{K}$ & $\mathrm{K} 1$ & POP \\
\hline 52 & 57655 & 57023 & 10006 \\
\hline 53 & 61841 & 61230 & 10217 \\
\hline 54 & 66133 & 65571 & 10452 \\
\hline 55 & 69907 & 69181 & 10659 \\
\hline 56 & 73707 & 72996 & 10856 \\
\hline 57 & 79198 & 78626 & 11153 \\
\hline 58 & 85473 & 84970 & 11395 \\
\hline 59 & 90488 & 90034 & 11625 \\
\hline 60 & 95272 & 94867 & 11840 \\
\hline 61 & 100009 & 99579 & 12046 \\
\hline 62 & 104590 & 104058 & 12273 \\
\hline 63 & 109195 & 108740 & 12513 \\
\hline 64 & 113970 & 113667 & 12792 \\
\hline 65 & 119706 & 119698 & 13088 \\
\hline 66 & 126910 & 127022 & 13423 \\
\hline 67 & 135215 & 135962 & 13791 \\
\hline 68 & 142997 & 144326 & 14143 \\
\hline 69 & 149857 & 151908 & 14490 \\
\hline 70 & 156694 & 159505 & 14843 \\
\hline 71 & 163897 & 167244 & 15187 \\
\hline 72 & 171139 & 175213 & 15515 \\
\hline 73 & 178399 & 183285 & 15860 \\
\hline 74 & 186921 & 192802 & 16275 \\
\hline 75 & 196758 & 203404 & 16693 \\
\hline 76 & 207745 & 214668 & 17097 \\
\hline 77 & 217669 & 224974 & 17466 \\
\hline 78 & 227336 & 234592 & 17817 \\
\hline 79 & 236754 & 243726 & 18151 \\
\hline 80 & 247825 & 254189 & 18518 \\
\hline 81 & 260649 & 265733 & 18860 \\
\hline 82 & 275015 & 278574 & 19162 \\
\hline 83 & 288519 & 288835 & 19434 \\
\hline 84 & 299150 & 296109 & 19668 \\
\hline
\end{tabular}

$K$ and $K 1$ : Beginning of year net stocks of fixed non-residential capital in manufacturing and non-manufacturing industries in 1971 prices.

$\mathrm{K}$ : See Section $\mathbf{V}$ for details.

K1: $\quad$ From Cansim Data Retrieval.

POP: Population in Canada, 15t, in thousands. Source: Cansim Data Retrieval. 
81016

$8102 \mathrm{C}$.

81036

8104C

$8105 C$

$8106 C$

$8107 C$

$8108 C \mathrm{Dg}$

8109 D S

$8110 \mathrm{C}$

$8111 \mathrm{C}$

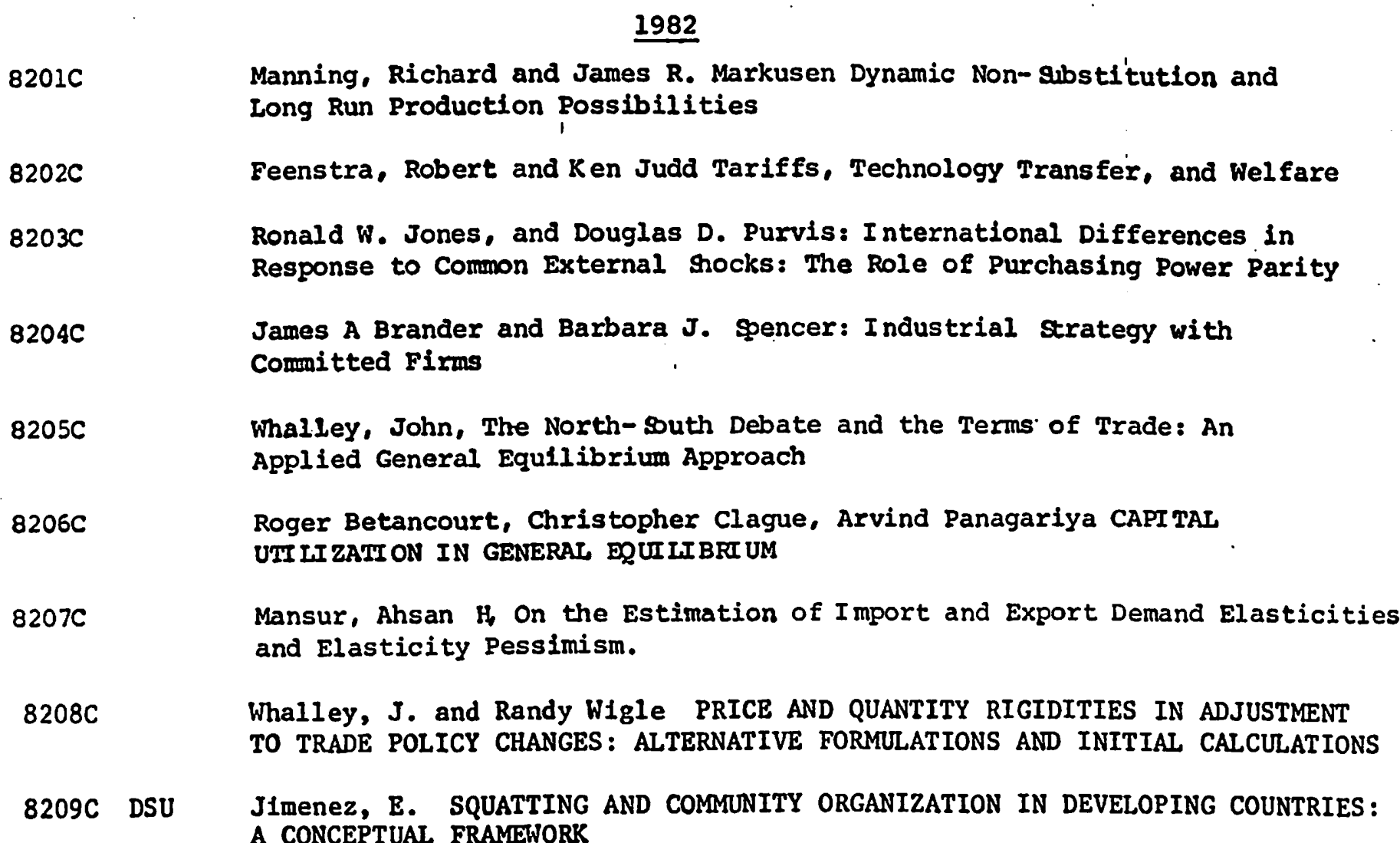

Markusen, James R. Factor Movements and Commodity Trade as Compliments: A Survey of some Cases.

Conlon, R.M. Comparison of Australian and Canadian Manufacturing Industries: Some Empirical Evidence.

Conlon, R.M. The Incidence of Transport Cost and Tariff Protection: Some Australian Evidence.

Laidler, David. On the Case for Gradualism.

Wirick, Ronald G. Rational Expectations and Rational

Stabilization Policy in an Open Economy

Mansur, Ahsan and John Whalley Numerical secification of Applied General Equilibrium Models: Estimation, Calibration, and Data.

Burgess, David F., Energy Prices, Capital Formation, and Potential GNP

Jimenez, E. and Douglas H. Keare. Housing Consumption and Income in the Low Income Urban Setting:. Estimates from Panel Data in El Salvador

Whalley, John Labour Migration and the North-South Debate'

Manning, Richard and John McMillan Government Expenditure and Comparative Advantage

Freid, Joel and Peter bowitt Why Inflation Reduces Real I nterest Rates

\section{$\underline{1982}$}


8210C Grossman, G.M. INTERNATIONAL COMPETITION AND THE UNIONIZED SECTOR

$8211 C$ La1dler,D. FRIEDMAN AND SCHWARTZ ON MONETARY TRENDS - A REVIEW ARTICLE $8212 C$ Imam, M.H: and Whalley, J. INCIDENCE ANALYSIS OP A SECTOR SPECIFIC MINIMUM
WAGE IN A THO SECTOR HARRIS-TODARO MODEL. 8213C Markusen, J.R. and Melvin, J.R. THE GAINS FROM TRADE THEOREM WITH INCREASING
RETURNS TO SCALE.

8214C INDUSTRIAL ORGANIZATION AND THE GENERAL EQUILIBRIUM COSTS OF PROTECTION IN

8215C La1dler, D. DID MACROECONOMICS NEED THE RATIONAL EXPECTATIONS REVOLUTION?

8216C Whalley, J. and Wigle, R. ARE DEVELOPED COUNTRY MULTILATERAL TARIFF REDUCTIONS NECESSARILY BENEFICIAL FOR THE U.S.?

8217C Bade, $R$. and Parkin, $M$. IS STERLING M3 THE RIGHT AGGREGATE?

8218C Kosch, B. FIXED PRICE EQUIIIBRIA IN OPEN ECONOMIES.

1983

$8301 \mathrm{~K}$ Kimbell, L.J. and Harr180n, G.W. ON THE SOLUTION OF GENERAL EQUILIBRIUM

8302C Melvin, J.R. A GENERAL EQUILIBRIUM ANALYSIS OF'.CANADIAN OIL POLICY. 8303C Markusen, J.R. and Svensson, L.E.O. TRADE IN COODS AND FACTORS WITH
INTERNATIONAL DIFFERENCES IN TECHNOLOGY.

8304C Mohammad, S. Whalley, J. RENT SEEKING IN INDIA: ITS COSTS AND POLICY
SIGNIFICANCE.

8305C DSU Jimenez, E. TENURE SECURITY AND URBAN SQUATTING.

8306C Parkin, M. WHAT CAN MACROECONOMIC THEORY TELL US ABOUT THE WAY DEFICITS
SHOULD BE MEASURED.

8307C Parkin, $M$. THE INFLATION DEBATE: AN ATTEMPT TO CLEAR THE AIR.

$8308 \mathrm{C}$ Wooton, I. LABOUR MIGRATION IN A MODEL OF NORTH-SOUTH TRADE.

8309C Deardorff, A.V. THE DIRECTIONS OF DEVELOPING COUNTRIES TRADE: EXAMPLES
FROM PURE THEORY.

8310C Manning, R. ADVANTAGEOUS REALLOCATIONS AND MULTIPLE EQUILIBRIA: RESULTS
FOR THE THREE-AGENT TRANSFER PROBLEM. 
$8311 C$ DSU Mohammad, S. and Whalley, J. CONTROLS AND THE INTERSECTORAL TERMS OF TRADE IN INDIA.

8312C - Brecher, Richard A. and Choudhr1, Ehsan U. NEW PRODUCTS AND THE FACTOR CONTENT OF INTERNATIONAL TRADE.

8313C Jones, R.W., Neary, J.P. and Ruane, F.P. TWO-WAY CAPITAL FLOWS: CROSSHAULING IN A MODEL OF FOREIGN INVESTMENT.

$8314 C$ DSU Follain, J.R. Jr. and Jimenez, E. THE DEMAND FOR HOUSING CHARACTERISTICS IN DEVELOPING COUNTRIES.

8315C Shoven, J.B. and Whalley, J. APPLIED' GENERAL EQUILIBRIUM MODELS OF TAXATION AND INTERNATIONAL TRADE.

8316C Boothe, Paul and Longworth Dav1d. SOME IRREGULAR REGULARITIES IN THE CANADIAN/U.S. EXCHANGE MARKET.

$8317 C$ Hamilton, Bob and Whalley, John. BORDER TAX ADJUSTMENTS AND U.S. TRADE.

8318C Neary, J. Peter, and Schweinberger, Albert G. FACTOR CONTENT FUNCTIONS AND THE THEORY OF INTERNATIONAL TRADE.

8319C Veall, M1chael R. THE EXPENDITURE TAX AND PROGRESSIVITY.

8320C Melvin, James R. DOMESTIC EXCHANGE, TRANSPORTATION COSTS AND INTERNATIONAL TRADE.

8321C Hamilton, Bob and Whalley, John. GEOGRAPHICALLY DISCRIMINATORY TRADE ARRANGEMENTS.

8322C Bale, Harvey Jr. INVESTMENT FRICTIONS AND OPPORTUNITIES IN BILATERAL U.S.-CANADIAN TRADE RELATIONS.

$8323 \mathrm{C}$ Wonnacott, R.J. CANADA-U.S. ECONOMIC RELATIONS--A CANADIAN VIEW.

8324C Stern, Robert M. U.S.-CANADIAN TRADE AND INVESTMENT FRICTIONS: THE U.S.: VIEW.

8325C Harrison, Glenn; H. and Kimbel1, Larry, J. HOW ROBUST IS NUMERICAL GENERAL EQUILIBRIUM ANALYSIS?

8326C Wonnacott, R.J. THE TASK FORCE PROPOSAL ON AUTO CONTENT: WOULD THIS SIMPLY EXTEND THE AUTO PACT, OR PUT IT AT SERIOUS RISK?

8327C Bradford, James C. CANADIAN DEFENCE TRADE WITH THE U.S. Conklin, David. SUBSIDY PACTS.

Rugman, Alan M. THE BEHAVIOUR OF U.S. SUBSIDARIES IN CANADA: IMPLICATIONS FOR TRADE AND INVESTMENTS. 


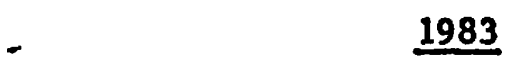

8328C Boyer, Kenneth D. U.S.-CANADIAN TRANSPORTATION ISSUES.

8329C Bird, Richard $M$. and Brean, Donald J.S. CANADA-U.S. TAX RELATIONS: ISSUES AND PERSPECTIVES.

$8330 \mathrm{C}$ Moroz, Andrew R. CANADA-UNITED STATES AUTOMOTIVE TRADE AND TRADE POLICY ISSUES.

8331C Grey, Rodney de C. and Curt1s, John. INSTITUTIONAL ARRANGEMENTS FOR U.S.-CANADIAN NEGOTIATIONS. PART I: CANADA-U.S. TRADE AND ECONOMIC ISSUES: DO WE NEED A NEW INSTITUTION? PART II: INSTITUTIONAL ARRANGEMENTS FOR MANAGING THE CANADA-U.S. ECONOMIC RELATIONSHIP.

\section{4}

8401C Harrison, Glenn W. and Manning, Richard, BEST APPROXIMATE AGGREGATION OF INPUT-OUTPUT SYSTEMS.

8402C Parkin, Michael. CORE INFLATION: A REVIEW ESSAY.

8403C Blomqvist, Ảke, and McMahon, Gary. SIMULATING COMMERICAL POLICY IN A SMALL, OPEN DUAL ECONOMY WITH URBAN UNEMPLOYMENT: A GENERAL EQUILIBRIUM APPROACH.

8404C Wonnacott, Ronald. THE THEORY OF TRADE DISCRIMINATION: THE MIRROR IMAGE OF VINERIAN PREFERENCE THEORY?

8405C Whalley, John. IMPACTS OF A 50\% TARIFE REDUCTION IN AN EIGHT-REGION GLOBAL TRADE MODEL.

8406C Harrison, Glenn $W$. A GENERAL EQUILIBRIUM ANALYSIS OF TARIFI REDUCTIONS.

8407C Horstmann, Ignatius and Markusen, James R. STRATEGIC INVESTMENTS AND THE DEVELOPMENT OF MULTINATIONALS. HYPOTHESIS IN THE FORWARD FOREIGN EXCHANGE MARKET: A SPECIFICATION ANALYSIS.

8409C Jones, Ronald $\mathrm{C}$. and Klerzkowsk1, Henryk. NEIGHBORHOOD PRODUCTION STRUCTURES WITH APPLICATIONS TO THE THEORY OF INTERNATIONAL TRADE.

$8410 \mathrm{C}$ Weller, Paul and Yano, Makoto. THE ROLE OF FUTURES MARKETS IN INTERNATIONAL TRADE: A GENERAL EỌUILIBRIUM APPROACH.

8411C Brecher, Richard A. and Bhagwat1, Jagdish N. VOLUNTARY EXPORT RESTRICTIONS VERSUS IMPORT RESTRICTIONS: A WELFARE-THEORETIC COMPARISON. 
1984.

8412C Ethier, W11fred J. ILLEGAL IMMIGRATION.

$8413 \mathrm{C}$ Eaton, Jonathon and Gene M. Grossman. OPTIMAL TRADE AND INDUSTRIAL POLICY UNDER OLIGOPOLY.

$8414 \mathrm{C}$ Wooton, Ian. PREFERENTIAI TRADING AGREEMENTS - A $3 \mathrm{xn}$ MODEL.

8415C Parkin, M1chael. DISCRIMINATING BETWEEN KEYNESIAN AND

CLASSICAL THEORIES OF THE BUSINESS CYCLE? JAPAN 1967-1982

8416C Deardorff, Alan V. FIRless FIRwoes: HOW PREFERENCES CAN INTERFERE WITH THE THEOREMS OF INTERNATIONAL TRADE.

8417C Greenwood, Jeremy. NONTRADED GOODS, THE TRADE BALANCE, AND THE BALANCE OF PAYNENTS.

8418C Blomqvist, Ake and Sharif Mohammad. CONTROLS, CORRUPTION, AND COMPETITIVE RENT-SEEKING IN LDCS.

8419C Grossman, Herschel I. POLICY, RATIONAL EXPECTATIONS, AND POSITIVE ECONOMIC ANALYSIS.

8420C Garber, Peter M. and Robert G. King. DEEP STRUCTURAL EXCAVATION? A CRITIOUE OF EULER EQUATION METHODS.

$8421 \mathrm{C}$ Barro, Robert J. THE BEHAVIOR OF U.S. DEFICITS.

8422C Persson, Torsten and Lars E.0. Svensson. INTERNATIONAL BORROWING AND TIME-CONSISTENT FISCAL POLICY.

8423C Obstfeld Maurice. Capital CONTROLS, THE DUAL EXChanGe RATE, AND DEVALUATION.

8424C Kuhn, Peter. UNION PRODUCTIVITY EFFECTS AND ECONOMIC EFFICIENCY.

8425C Hamilton, Bob and John Whalley. TAX TREATMENT OF HOUSING IN A DYNAMIC SEOUUENCED GENERAL EOUUILIBRIUM MODEL.

$\because 426 \mathrm{C}$ Hamilton, Bob, Shar1f Mohammad, and John Whalley, RENT SEEKING AND THE NORTH-SOUTH TERMS OF TRADE.

8427C Adams, Charles and Jercmy Greenwood. DUAL EXCHANGE RATE SYSTEMS AND CAPITAL CONTROLS: AN INVESTIGATION.

8428 Loh, Choon Cheong and Michael R. Veall. A NOTE ON SOCIAL SECURITY AND PRIVATE SAVINGS IN SINGAPORE.

8429 Whalley, John. RFGRESSION OR PROGRESSION: THE TAXING OUESTION OF INCIDENCE ANALYSIS.

8430 Kuhn, Peter. WAGES, EFFORT, AND INCENTIVE-COMPATIBILITY IN LIFE-CYCLE EMPLOYMENT CONTRACTS . 
8431 Greenwood, Jeremy and Kent P. Kimbrough. AN INVESTIration IN THE THEORY OF FOREIGN EXCHANGE CONTROLS.

8432 Greenwood, Jeremy and Kent P. Kimbrough. CAPITAL CONTROLS AND THE INTERNATIONAL TRANSMISSION OF FISCAL POLICY.

8433 : Nguyen, Trien Trien and John Whalley. EỌUILIBRIUM UNDER PRICE CONTROLS WITH ENDOGENOUS TRANSACTIONS COSTS.

8434 Adams, Charles and Russell S. Boyer. EFFICIENCY AND A SIMPLE MODEL OF EXCHANGE RATE DETERMINATION.

8435 Kuhn, Peter. UNIONS, ENTREPRENEURSHIP, AND EFFICIENCY.

8436 Hercowitz, Zvi and Efraim Sadka. ON OPT IMAL CURRENCY. SUBSTITUTION POLICY AND PUBLIC PINANCE.

8437 Lenjosek, Gordon and John Whalley. POLICY EVALUATION IN A SMALL OPEN PRICE TAKING ECONOMY: CANADIAN ENERGY POLICIES.

8438 Aschauer, David and Jeremy Greenwood. MACROECONOMIC EFFECTS OF FISCAL POLICY.

8439C Hercowitz, Zvi. ON THE DETERMINATION OF THE EXTERNAL DEBT: THE CASE OF ISRAEL.

8440C Stern, Robert M. GLOBAL DIMENSIONS AND DETERMINANTS OF INTERNATIONAL TRADE AND INVESTMENT IN SERVICES.

$8441 \mathrm{C}$ Deardorff, Alan V. COMPARATIVE ADVANTAGE AND INTERNATIONAL TRADE AND INVESTMENT IN SERVICES.

8442C Daly, Donald J. TECHNOLOGY TRANSFER AND CANADA'S COMPETITIVE PERFORMANCE.

8443C Grey, Rodney de C. NEGOTIATING ABOUT TRADE AND INVESTMENT IN SERVICES.

8444C Grossman, Gene M. and Carl Shapiro. NORMATIVE ISSUES RAISED BY INTERNATIONAL TRADE IN TECHNOLOGY SERVICES.

3445C Chant, John F. THE CANADIAN TREATMENT OF FOREIGN BANKS: A CASE STUDY IN THE WORKINGS OF THE NATIONAL TREATMENT APPROACH.

8446C Aronson, Jonathan D. and Peter F. Cowhey. COMPUTER, DATA PROCESSING, AND COMMNICATION SERVICES.

8447C Feketekuty, Geza. NEGOTIATING STRATEGIES FOR LIBERALIZING TRADE AND INVESTMRNT IN SERVICES.

8448C Harrison, Glenn, W. and E.E. Rutstrom. THE EFFECT of MANUTACTURING SECTOR PROTECTION ON ASEAN AND AUSTRALIA: A GENERAL ENUILIBRIUM ANALYSIS. 
$8501 \mathrm{C}$

8502C Horstmann, Ignatius and James R. Markusen. UP YOUR AVERAGE COST CURVE: INEFFICIENT ENTRY AND THE NEW PROTECTIONISM.

8503C Gregory, Allan $W$. TESTING INTEREST RATE PARITY AND RATIONAL EXPECTATIONS FOR CANADA AND THE UNITED STATES.

$8504 \mathrm{C}$ Kuhn, Peter and Ian Hooton. INTERNATIONAL FACTOR MOVEMENTS IN THE PRESENCE OF A FIXED FACTOR.

8505C Wong, Kar-yiu. GAINS FROM GOODS TRADE AND FACTOR MOBILITY.

8506C Weller, Paul and Makoto Yano. FUTURES MARKETS, REAL INCOME, AND SPOT PRICE VARIABILITY: A GENERAL EỌUII IBRIUM APPROACH.

8507C Diewert, H.E. THE EFFECTS OP AN INNOVATION: A TRADE THEORY APPROACH.

8508C Ethier, Wilfred J. POREIGN DIRECT INVESTMENT AND THE MULTINATIONAL FIRM.

8509C Dinopoulos, Elias. INSIDE THE BLACK BOX: (IN) TANGIBLE ASSETS, INTRA-INDUSTRY INVESTMENT AND TRADE.

8510C Jones, Richard, John thalley, and Randall Higle. REGIONAL IMPACTS OF TARIFFS IN CANADA: PRELIMINARY RESULTS FROM A SMALL DIMENSIONAL NUMERICAL GENERAL EOUUILIBRIUM MODEL.

8511C Whalley, John. HIDDEN CHALLENGES IN RECENT APPLIED GENERAL EQUILIBRIUM EXERCISES.

8512C Smith, Bruce. SOME COLONIAL EVIDENCE ON TWO THEORIES OF MONEY: MARYLAND AND THE CAROLINAS.

3513C Grossman, S.J., A. Melino, and R.J. Shiller. ESTIMATING THE CONTINUOUS TIME CONSUMPTION BASED ASSET PRICING MODEL.

8514C Romer, Paul R. TAX EFFECTS AND TRANSACTION COSTS FOR SHORT TERM MARKET DISCOUNT BONDS.

8515C McCallum, Bennett T. ON CONSEOUUENCES AND CRITJCISMS OF MONETARY TARGETING.

8516C Dinopoulos, Elias and Ian Wooton. A NORTH-SOUTH MODEL OF INTERNATIONAL JUSTICE.

8517C Huffman, Gregory W. A DYNAMIC EQUILIBRIUM MODEL OF ASSET PRICES AND TRANSACTION VOLUME.

8518C Huffman, Gregory W. AN ALTERNATIVE VIEW OF OPTIMAL SEIGNIORAGE.

8519C Huffman, Gregory W. ASSET PRICING WITH HETERGENEOUS ASSETS. 


\section{$\underline{1985}$}

8520C Hercowitz, Zvi. THE REAL INTEREST RATE AND AGGREGATE SUPPLY. 